\title{
O PAPEL DA INTERPROFISSIONALIDADE NO CUIDADO DA PESSOA IDOSA: UM RELATO DE EXPERIÊNCIA
}

\author{
The role of interprofessionality in the care of the elderly: A report \\ of experience
}

Guilherme Parreira Vaz ${ }^{1}$, Evandro Leite Bitencourt ${ }^{1,2}$

\begin{abstract}
RESUMO
Qual o papel da interprofissionalidade no cuidado da pessoa idosa? Partindo desse questionamento, o objetivo deste artigo é descrever e discutir as funções desempenhadas pelo trabalho interprofissional em saúde para o cuidado do público idoso. Para tal, foram descritas e interpretadas experiências vivenciadas por um grupo de estudantes da disciplina de Saúde da Família I, do curso de Medicina da Universidade Federal do Tocantins, Câmpus Palmas-TO. Na metodologia foi utilizado um estudo descritivo do tipo relato de experiência a partir das aulas práticas realizadas no Parque Municipal da Pessoa Idosa Francisco Xavier do município de Palmas. Os resultados apontam para a necessidade de aprimoramento da interprofisionalidade nas equipes de saúde pelos seguintes motivos: a existência de especificidades para o cuidado do idoso dependentes da atuação interprofissional; a melhoria da humanização na saúde ser potencializada pelo trabalho integrado, assim como o papel formativo e socializador da interdisciplinaridade para se garantir a autonomia e qualidade de vida na terceira idade. $O$ trabalho permitiu ainda a reflexão sobre a formação dos profissionais de saúde, sendo importante por ressaltar necessidade de capacitação dos servidores da saúde para a execução eficaz dos princípios defendidos pelo Sistema Único de Saúde (SUS).
\end{abstract}

Palavras- Chave: Interprofissionalidade. Saúde. Idoso.

Citação: Vaz GP, Bitencourt EL. (2020) Impactos do processo de informatização para o ensino e funcionamento dos serviços em saúde: um relato de experiência. Revista de Patologia do Tocantins, 7(1):.71-77

Instituição: ${ }^{1}$ Acadêmico(a) de Medicina, Universidade Federal do Tocantins, Tocantins, Brasil. ${ }^{2}$ Graduado em Química, Mestre em Química, Pesquisador Instituto Médico Legal do Tocantins (IML/TO), Palmas, Brasil.

Autor correspondente: Guilherme Parreira Vaz; parreirameduft@gmail.com

Editor: Guedes V. R. Medicina, Universidade Federal do Tocantins, Brasil.

Publicado: 09 de junho de 2019.

Direitos Autorais: (C) 2020 Vaz et al. Este é um artigo de acesso aberto que permite o uso, a distribuição e a reprodução sem restrições em qualquer meio, desde que o autor original e a fonte sejam creditados. Conflito de interesses: os autores declararam que não existem conflitos de interesses. 


\section{INTRODUÇÃO}

A interdisciplinaridade e a interprofissionalidade, embora sejam conceitos distintos, relacionam-se a um mesmo eixo comum pautado na integração de trabalhadores em prol de determinada ação. Essa perspectiva de trabalho em equipe é bastante recente e estudos direcionados à efetividade de tal modelo demonstram-se em expansão. Entende-se por interdisciplinar aquela educação a qual promove a síntese, visando à construção de significados comuns. Por outro lado, a Educação Interprofissional (EIP) foi incluída na Conferência Alma-Ata em 1978 representando uma das estratégias para se promover a saúde para todos no ano 2000 (LIMA et al., 2018).

Nesse contexto, é importante reconhecer a existência de modelos educacionais em andamento que preconizam esse aspecto de cooperação coletiva vinculada ao processo de formação em saúde. Um exemplo de relevância é a Residência Multiprofissional em Saúde (RMS). Essa pode ser caracterizada como um tipo de pós-graduação realizada a partir do trabalho em saúde. Sendo assim, a primeira atividade para este fim foi desenvolvida no ano de 1976, na Escola de Saúde Pública do Rio Grande do Sul (RS), contemplando a formação integrada de enfermeiros, médicos, assistentes sociais e médicos veterinários (SILVA, 2018).

Todavia, é válido ressaltar que a consolidação de um sistema de saúde homogêneo, no sentido de interligação e prática conjunta dos serviços, ainda é um grande desafio no país. Isso é evidenciado a começar pelas disciplinas ofertadas nos cursos de graduação nacionais. No ensino superior, sobretudo em formações nas áreas de Biológicas e da Saúde, predominam cadeiras isoladas e cursos independentes até mesmo em grandes universidades. Além disso, podem ser apontados outros obstáculos significativos que comprovam tal realidade: a compartimentalização dos saberes; a abordagem biomédica individual e fragmentação na atenção à saúde, decorrentes da hierarquização em saúde ainda persistente, são evidências da problemática existente que afeta o desempenho de princípios básicos defendidos pelo Sistema Único de Saúde (SUS) no Brasil (LIMA et al., 2018).

Dessa maneira, o trabalho interprofisional em saúde é apontado por diversos autores como uma estratégia valiosa para a superação dos desafios complexos do setor de saúde brasileiro concretizando, também, a interdisciplinaridade. Essa se relaciona às disciplinas envolvidas nas áreas de conhecimento enquanto aquele está diretamente ligado à prática profissional, que invariavelmente é associada aos conhecimentos consolidados ao longo da formação do trabalhador. É importante enfatizar esse aspecto indissociável entre ambas no intuito de se entender a importância da aplicação teórica na prática do serviço, mas de forma colaborativa e não individual (TAVARES; SILVA, 2016).

Nessa perspectiva, a Saúde da Família representa uma vertente considerável em relação ao desenvolvimento da interprofisionalidade que, tem como um de seus produtos finais, tão somente o aprimoramento da rede de atenção primária, berço da humanização no atendimento e bem- estar dos cidadãos. Sendo assim, um estudo transversal e descritivo de abordagem qualiquantitativa foi desenvolvido com trabalhadores de unidades de saúde da família (USFs) dos cinco distritos sanitários (DSs) do município de João Pessoa, capital da

Paraíba. Esse mostrou fatores relevantes que apontam para a necessidade de se desenvolver a integração entre os trabalhadores, nos moldes da EIP, para a obtenção de resultados mais promissores no funcionamento das equipes de saúde (FARIAS et al., 2018).

Dentre os resultados mais relevantes, destacase a necessidade dos profissionais em materializar a interdisciplinaridade em práticas interprofissionais colaborativas; ações de gestão voltadas para essas práticas; a educação permanente para o enfrentamento das dificuldades de integração e o investimento dos próprios trabalhadores da saúde nessa direção. Tal realidade vivenciada nessa região é passível de ser estendida para muitos municípios do território e, a partir disso, a relevância de se discutir e aprofundar nas pesquisas relacionadas a essa temática toma grandes proporções no campo da saúde (FARIAS et al., 2018).

É neste contexto no qual o objetivo deste trabalho é descrever e discutir as experiências vivenciadas por um grupo de estudantes do curso de Medicina da Universidade Federal do Tocantins (UFT), Câmpus Palmas, sobre o papel da interprofisionalidade para o cuidado da pessoa idosa. Tal realidade foi vivenciada a partir das vivências práticas realizadas na disciplina de Saúde da Família I, que ocorreram no Parque Municipal da Pessoa Idosa Francisco Xavier.

A realização deste trabalho se justifica pela importância em se conhecer e aprimorar metodologias integrativas para a execução dos serviços de saúde no Brasil. É fato que a Nação vivencia atualmente um processo de envelhecimento significativo o qual promove impactos de grandes proporções em diversas esferas, exigindo adaptações para o atendimento satisfatório da população idosa. Essa cresce progressivamente à medida que a expectativa de vida do brasileiro aumenta. Sendo assim, entender e aplicar o trabalho intersetorial entre os profissionais de saúde no intuito de se garantir a humanização e eficiência dos serviços são ações extremamente relevantes cujo alicerce está na formação interdisciplinar permanente (MENEZES et al., 2015).

Dessa maneira, as experiências práticas vivenciadas durante o longo processo de formação dos estudantes de graduação das diversas ciências na saúde contribuem para o processo de reflexão sobre sua própria aprendizagem. Nesse sentido, o exercício do trabalho coletivo em prol do bem-estar de populações específicas como uma comunidade de idosos, as quais possuem suas singularidades e costumes, requer capacitação e atitude. Além disso, é preciso o desenvolvimento de outras habilidades que, muitas vezes, somente são consolidadas a partir do contato direto visto no campo de ensino-aprendizagem (SILVA; SILVA, 2008).

\section{METODOLOGIA}

Trata-se de um estudo descritivo do tipo relato de experiência elaborado no contexto da disciplina Saúde da 
Família I, ofertada no terceiro período do curso de Medicina da UFT, Câmpus Palmas. Essa cadeira tem como objetivo permitir o aprofundamento de conhecimentos básicos dos alunos sobre o SUS e seu funcionamento na prática médica, sendo isso feito por meio de aulas teóricas e práticas realizadas tanto nas dependências da instituição de ensino quanto em outros espaços, como UBSs, dentre outros locais.

Nesse sentido, como ferramenta metodológica o grupo de cinco estudantes pôde executar atividades de observação, registro de informações e ações protagonistas em prol da reeducação em saúde com outros profissionais da área, preconizando um trabalho coletivo interprofissional. Esse teve como público alvo 150 cidadãos idosos que frequentam diariamente o Parque Municipal da Pessoa Idosa de Palmas Francisco Xavier, local estabelecido pelos professores da disciplina como parte integrante dos lugares em que eles deveriam fazer as três semanas de vivências a campo.

Todas as atividades foram desenvolvidas em três quartas-feiras, pela manhã, no segundo semestre de 2018. Seu início ocorreu na última semana de outubro e o término na segunda semana de novembro. Para tal, foram orientadas e supervisionadas pela professora responsável pelo grupo, que também estabeleceu previamente um roteiro de ações a serem seguidas pelos discentes. Em um primeiro momento foi realizado o reconhecimento do território por meio da observação crítica do funcionamento e estrutura do parque. Posteriormente, os acadêmicos tiveram um contato direto com os residentes no local o que permitiu a definição de uma melhor forma metodológica de abordagem, optando-se pela conversa e auxílio aos funcionários no atendimento aos idosos como forma de aproximação e estudo da realidade.

Além disso, em cumprimento às propostas préestabelecidas na ementa da matéria de graduação, os alunos elaboraram uma proposta de intervenção social, com o auxílio de uma equipe de estratégia da saúde da família, a qual colaborou dando suporte na construção e execução da ação. Essa foi planejada a partir da análise crítica e diálogo junto aos idosos, que permitiram enxergar as necessidades daquela comunidade. Dessa maneira, o trabalho interprofissional de intervenção teve como ferramentas de execução a palestra expositiva; dinâmicas de aprendizagem e momento de socialização.

Por sua vez, o eixo temático abordado na ação interventiva foi "Substituição alimentar", tendo em vista o número de idosos hipertensos, frequentes no parque e que fazem acompanhamento periódico com a equipe da Unidade Básica de Saúde da quadra 403 Sul, assim como casos de Síndrome Metabólica diagnosticados pelo médico responsável nessa área de abrangência.

\section{RESULTADOS E DISCUSSÃO}

\section{O reconhecimento do território de vivências}

No primeiro dia de vivência, os cinco discentes tiveram a oportunidade de conhecer estruturalmente e funcionalmente o Parque Municipal da Pessoa Idosa Francisco
Xavier, local de realização dos três dias de aulas práticas. Nesse sentido, o estabelecimento está situado na Quadra 301 Sul, Avenida NS 1, 2-652, Plano Diretor Sul no município de Palmas-TO.

O simples processo de locomoção até o local já representou uma experiência significativa aos graduandos, visto que a divisão dos grupos já havia sido determinada, permitindo uma maior integração entre os membros de uma mesma turma do curso. Sendo assim, esses contaram com veículos dos colegas de equipe durante as semanas em que estiveram a campo. A foto abaixo ilustra a chegada do parque, na qual há a entrada principal para a recepção, ambiente em que os estudantes foram recebidos e orientados quanto aos diversos aspectos desde a fundação até os dias atuais da instituição.

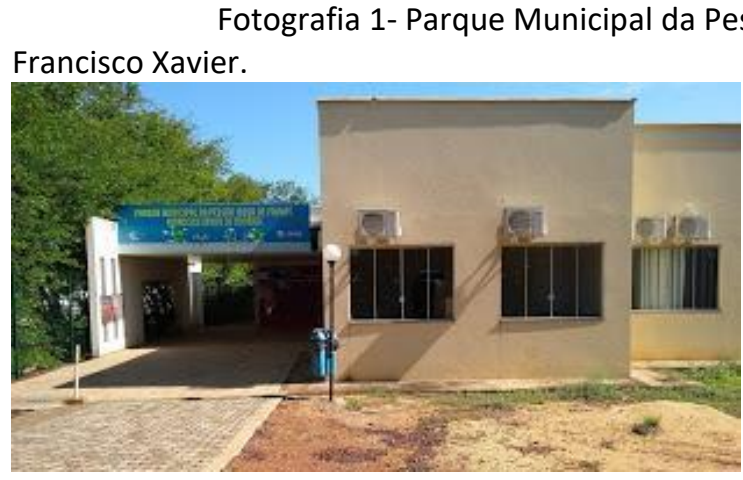

Fonte: Google imagens.

Dessa maneira, foi possível entender o contexto histórico de fundação e organização do instituto. Para tal, neste primeiro dia os acadêmicos conversaram com a coordenadora desse, que prontamente explanou a cerca da importância e dos desafios enfrentados não apenas por esse, mas vários órgãos públicos e gratuitos em relação às suas necessidades para permanência na oferta dos serviços.

Nesse contexto, uma breve reflexão a cerca do papel e impacto exercido pelo Parque da Pessoa Idosa de Palmas pôde ser feita, despertando a atenção dos universitários sobre as especificidades do cuidado para com esse público em específico. Isso foi evidenciado ao conhecer melhor sobre o início do funcionamento do ambiente e seu desenvolvimento. O local foi entregue à população de Palmas em fevereiro de 2016, tendo sua primeira atividade junto ao público idoso ocorrida em agosto de 2016. Desde então cerca de 600 idosos já frequentaram o recinto sendo atendidos por equipes interdisciplinares e multiprofissionais em saúde.

Além disso, a observação crítica de aspectos estruturais permitiu identificar inúmeros recursos de suporte que a pessoa na terceira idade precisa, dentre eles: espaço para descanso e tranquilidade, como as áreas verdes internas; ambiente de convívio coletivo, presentes por meio das salas e varandas, bem como área para práticas esportivas comtemplada a partir de uma quadra poliesportiva nos fundos do parque.

\section{O primeiro contato com os idosos e a troca de experiências}

A mudança da sala de aula teórica para o campo prático de ensino causa, por si só, experiências muito individuais e únicas. Os estudantes tiveram a oportunidade de conhecer e vivenciar o convívio com "pacientes" os quais também contribuíram para processo de formação médica dos mesmos. Nesse sentido, é válido ressaltar que a insegurança, o medo e 
a ansiedade diante dos idosos foram reações predominantes entre os alunos em um primeiro momento.

Outro aspecto relevante é a confiança depositada nos acadêmicos por parte dos membros da terceira idade. Expressões como "doutor" e "nossos médicos" foram amplamente empregadas por eles desde o primeiro dia de vivência dos discentes. Tal fato resultou também em uma maior responsabilização desses sobre suas ações, ainda que supervisionados pelo professor e outros profissionais.

Por outro lado, a receptividade com a qual os alunos foram recebidos possibilitou uma maior interação entre os graduandos e os senhores e senhoras que se encontravam no local. A troca de informações diversas sobre hábitos alimentares, formas de controle da ansiedade, assim como maneiras diferentes de se enxergar o processo fisiológico de envelhecimento permitiram aos estudantes novas perspectivas e pontos de vista sobre o decorrer da vida e a morte.

É neste contexto que foi possível, por parte do grupo de vivências, começar a identificar o cenário de trabalho que possivelmente irão encontrar após o fim de sua faculdade. Reflexões a cerca do envelhecimento e aumento da expectativa de vida da população mundial também foram feitas entre os alunos, professor e o médico responsável pela equipe de saúde da família local. Essas apontaram para a grande necessidade de se trabalhar o multiprofissionalismo para o cuidado de populações cada vez mais velhas e heterogêneas, as quais apresentam múltiplas especificidades de cuidado e tratamento.

Por sua vez, na mesma ocasião, o grupo de vivências teve a oportunidade de executar procedimentos básicos de atenção primária já aprendida no início da graduação, como a aferição de pressão e a medição de altura. Essa foi uma das ações mais gratificantes e estimulantes desempenhadas pelos mesmos neste dia, sendo feita com o apoio da equipe de enfermagem e do médico especialista em Medicina da Família e Comunidade. A imagem abaixo retrata o grupo de vivências e a professora responsável pelo mesmo numa das salas de convivência situada nas dependências do Parque da Pessoa Idosa de Palmas.

Fotografia 2- Acadêmicos em seu primeiro dia de vivência.

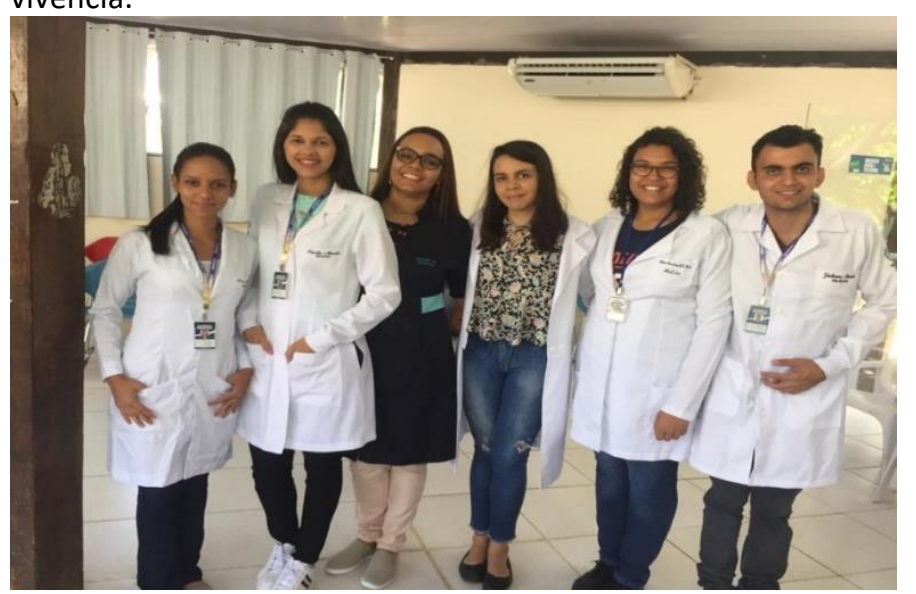

Fonte: (própria).

\section{A interprofissionalidade no cuidado da pessoa idosa.}

As melhorias nas condições de vida dos cidadãos nas últimas décadas permitiram o aumento na expectativa de vida de milhões de pessoas. Esse fato pode ser explicado pelos avanços nas tecnologias industriais, de informação e mecânicas que revolucionaram os processos de geração de energia e de produção. Sendo assim, os profissionais da saúde inseridos nessa era da modernidade trabalham para o desenvolvimento e progresso de ações e programas que ampliem a qualidade de vida, independência e autonomia da pessoa idosa. Tal desafio exige atitudes que se estendem desde investimentos governamentais até o protagonismo do trabalho em equipe de diversos profissionais (BARBOSA et al.,2016).

Nesse contexto, desde o primeiro dia de aula prática os discentes já tiveram suas percepções sobre a forma pela qual o trabalho coletivo é estabelecido, visto que acompanharam e colaboraram juntamente com os agentes de saúde, enfermeiro e médico da área de abrangência para o cuidado dos idosos frequentes no estabelecimento. Por conseguinte, no segundo dia de vivência foi possível um olhar ampliado sobre as especificidades do atendimento ao cidadão da terceira idade.

Dessa forma, a presença da profissional graduada em odontologia no Parque da Pessoa Idosa representou impacto positivo e desafiador aos discentes do curso de medicina da Universidade Federal do Tocantins. A atividade de reeducação em saúde bucal desempenhada pela profissional com o auxílio dos alunos trouxe para a prática cotidiana a integração entre as profissões, oque infelizmente não é comum durante os longos anos de graduação. Foi possível a associação entre conhecimentos básicos da formação em saúde com procedimentos específicos das ciências odontológicas.

Ademais, a percepção diversificada do conceito de saúde aplicada permitiu aos alunos entender a complexidade existente na atuação conjunta de diferentes trabalhadores da saúde, mas a importância e a eficiência que isso proporciona na promoção da qualidade de vida dos assistidos. Abaixo a fotografia ilustra o momento de palestra de conscientização em saúde bucal desenvolvida pela odontóloga com o auxílio dos discentes de medicina presentes na vivência.

Fotografia 3- Ação interdisciplinar entre estudantes de Medicina e profissional da Odontologia.

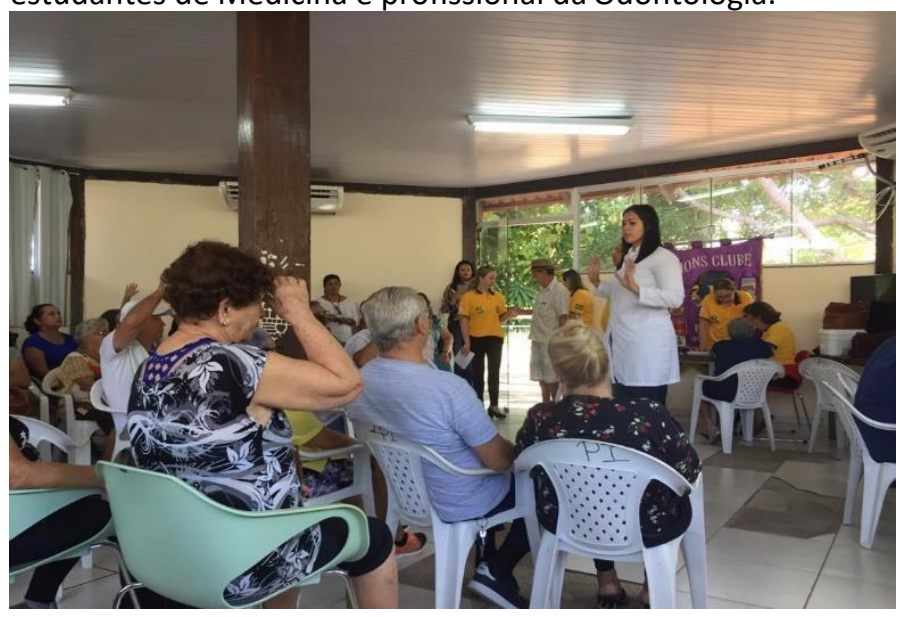

Fonte: (própria).

Assim, concomitantemente à atividade de reeducação em saúde realizada junto à dentista da equipe de estratégia da saúde da família, foi possível o acompanhamento do médico, que na ocasião realizou o rastreio de pacientes idosos que 


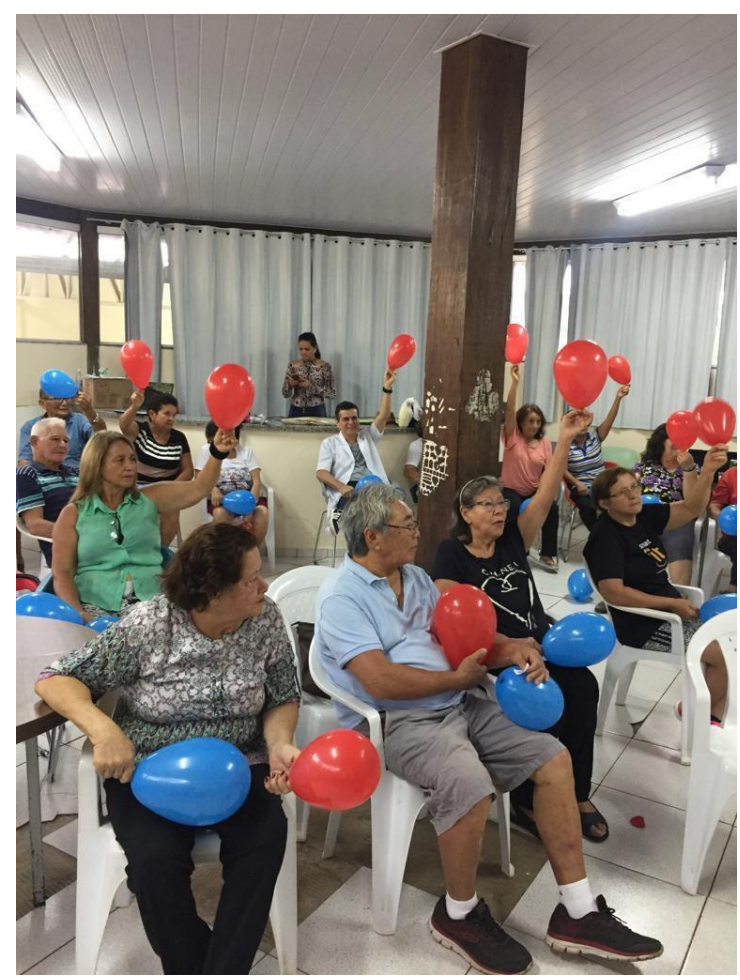

Fonte: própria.

Em um último momento, a mesa redonda possibilitou um contato mais próximo entre os acadêmicos e a população de terceira idade, o que foi bastante produtivo para ambos os envolvidos. $O$ uso de produtos industrializados nas mesas, como refrigerantes, biscoitos e salgadinhos serviu alertar ao público sobre os malefícios do consumo excessivo de açúcar e sal, por exemplo, resultando em debates relevantes e trocas de saberes.

Um ponto de destaque foi o entendimento dos estudantes sobre as diferentes formas de linguagem as quais a população idosa utiliza para expressar seus conhecimentos, o nome de determinada doença, por exemplo. Muitas vezes situações de constrangimento e falta de comunicação acontecem entre os profissionais de saúde e demais cidadãos devido a falhas no diálogo básico entre os envolvidos, inclusive durante as disciplinas práticas dos cursos de graduação.

Isso criou a necessidade de reflexão dos graduandos sobre a necessidade de se adaptar o atendimento para favorecer a promoção de saúde e bem-estar de modo igualitário a todos. Na figura abaixo se mostra a mesa redonda, estratégia utilizada pelos discentes para a aproximação e educação em substituição alimentar.

Fotografia 7- Discussão em mesa redonda sobre substituição alimentar do idoso.

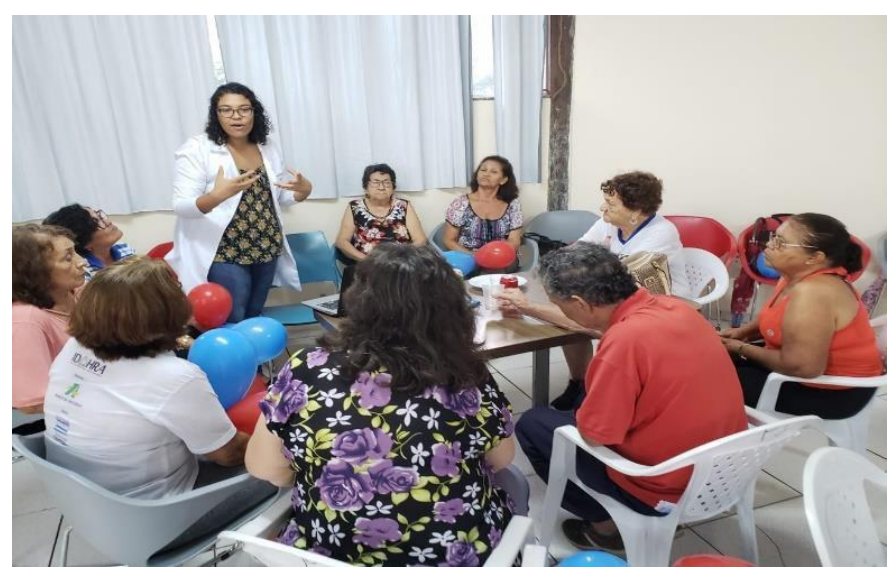

Fonte: própria.

\section{CONCLUSÃO}

O trabalho em saúde pautado na interprofissionalidade exerce papel significativo para a promoção da melhoria e humanização do Sistema único de Saúde (SUS). Por meio das experiências vivenciadas pelo grupo de estudantes foi possível evidenciar as contribuições das diversas ciências da saúde que se integra para um único fim, que é o bem-estar do indivíduo assistido.

Além disso, o conhecimento de práticas integradoras entre as disciplinas, promovendo a interdisciplinaridade entre os protagonistas da saúde, mostrou-se viável e passível de execução mediante as estratégias de capacitação e formação dos profissionais desde os anos iniciais da graduação. Nesse sentido, o presente trabalho representa contribuição significativa ao enfatizar a importância da educação interprofissional em saúde a partir dos primórdios do ensino superior no país, ressaltando a possibilidade e necessidade de se aprimorar os sistemas educacionais e de saúde nacionais a partir da educação permanente em saúde interdisciplinar e interprofissional.

\section{REFERÊNCIAS BIBLIOGRÁFICAS}

1. BARBOSA, A.S et al. A interdisciplinaridade vivenciada em um grupo de idosos de uma unidade de saúde da família do Recife. Rev. APS. v. 19(2): p.315 - 320. Abr./jun, 2016.

2. BATISTA, N.A e BATISTA, S.H.S. A prática como eixo da aprendizagem na graduação médica. Editora Unifesp. v. 1, p. 101-115, 2008.

3. FARIAS, D.N et al.Interdisciplinaridade e Interprofissionalidade na Estratégia Saúde Da Família. Revista Trabalho, Educação e Saúde. 16 n. 1, p. 141-162, jan./abr, 2018.

4. LIMA, V.V et al. Challenges in the education of health professionals: an interdisciplinary and interprofessional approach. Revista Interface. v. 22(Supl. 2): p.1549-62, 2018.

5. MENEZES, M.F. G et al. Reflexões sobre alimentação saudável para idosos na agenda pública 
6. brasileira. Revista Brasileira de Geriatria e Gerontololgia. v 18(3): p.599-610, 2015.

7. SILVA, L.B. Residência Multiprofissional em Saúde no Brasil: alguns aspectos da trajetória histórica. Revista Katál. v. 21, n. 1, p. 200-209, jan./abr, 2018

8. TAVARES, M.F. L e SILVA, D.A.J. Ação intersetorial: potencialidades e dificuldades do trabalho em equipes da Estratégia Saúde da Família na cidade do Rio de Janeiro · Revista Saúde em Debate. v. 40, n. 111, p. 193-205, out/ dez,2016. 